\title{
Enhancement of concrete surface by coating with cement-based alkaline activator
}

\author{
Ashraf M. Heniegal ${ }^{1} \cdot$ Alan Richardson ${ }^{2} \cdot$ Omar Mohamed Omar Ibrahim $^{3}$
}

Received: 30 December 2019 / Accepted: 6 April 2020 / Published online: 9 April 2020

(c) Springer Nature Switzerland AG 2020

\begin{abstract}
The exterior surface damage of concrete is a major problem for sub-structures and super-structures which are manufactured from concrete. In recent years, the protection of concrete exterior surfaces has attracted the attention of many researchers. This paper shows that alkaline activator coating materials (AACM) are used for curing concrete exterior surfaces. The curing of the concrete exterior surface with AACM helps to significantly reduce porosity in most products of building construction materials like hardened concrete and mortar plasters when they applied to their exterior surface. A chemical reaction occurs with unreactive Portland cement on the concrete exterior surface that always binds silicates to the concrete surface which in turn leads to decrease sucking of water into the concrete exterior surface. AACM can penetrate with the concrete exterior surface which helps to increase the deepness of waterproofing applied to the concrete exterior surface. The operation is simple to use, leaves no remnant and dries in a short time. It is ideal when it's used on the concrete exterior surface and additionally it is appropriate for types of concrete exterior faces. The results presented the positive effect of alkaline activator coating materials AACM on the visual appearance, water-absorption, water-penetration, and sulfate attack. Alkaline activator coating has the same performance, but it would be cheaper when compared to the oil-based products.
\end{abstract}

Keywords Alkaline activator coating materials (AACM) - Cement $\cdot$ A concrete exterior surface $\cdot \mathrm{NaOH} \cdot \mathrm{Na}_{2} \mathrm{SiO}_{3}$. $\mathrm{K}_{2} \mathrm{OxSiO}{ }_{2} \cdot \mathrm{Na}_{2} \mathrm{SO}_{4}$

\section{Introduction}

Concrete structures science is the most studied in the world. One technique for providing improved maintenance is the application of external surface maintenance to provide protection of the surface by increasing the external surface penetration impedance for liquids. External surface penetration impedance materials for liquids are classified into silane-based, silicate-based, oil-based, water-based, and chemical-based. Silane-based materials consist of many layers that resist water from penetrating the cover of concrete. Silicate-based surface penetration materials filled in the surface in the cover of concrete. The impedance of external surface penetration has recently been developed because the materials have low viscosity. However, these materials properties remain largely unknown. The main Ingredients of silicate-based surface penetration impedance materials are $\mathrm{Na}_{2} \mathrm{SiO}_{3}$ and $\mathrm{K}_{2} \mathrm{O} \times \mathrm{SiO}_{2}$. The $\mathrm{Na}_{2} \mathrm{SiO}_{3}$ based external surface penetration impedance material that has low viscosity as used in this paper, is largely composed of silicate, sodium, and water [1]. $\mathrm{Na}_{2} \mathrm{SiO}_{3}$ can be used to protect metals external surfaces from corrosion for years as well as the concrete external surface [2]. Silicate-based surface penetration

Omar Mohamed Omar Ibrahim, omar.ibrahim@suezuniv.edu.eg; Ashraf M. Heniegal, ashraf.heneagal@suezuni.edu.eg; Alan Richardson, alan.richardson@northumbria.ac.uk | ${ }^{1}$ Department of Civil Engineering, Faculty of Engineering, Suez University, Suez, Egypt. ${ }^{2}$ Department of Mechanical and Construction Engineering, Faculty of Engineering and Environment, Northumbria University, Newcastle upon Tyne, Tyne and Wear NE1 8ST, UK. ${ }^{3}$ Civil Construction and Architecture Department, Faculty of Industrial Education, Suez University, Suez, Egypt. 
materials filled off the external surface voids in the cover of concrete also called $\mathrm{Na}_{2} \mathrm{SiO}_{3}$ solutions, which are mostly used in industry, especially in the construction building materials. However, these materials (water glass) are also used as a reactant during the formation of geo-polymers $[3,4]$. It is also used in construction as a mineral binder (inorganic materials) for many applications [5]. $\mathrm{Na}_{2} \mathrm{SiO}_{3}$ binder can be used for agglomeration processes very successfully which combines or consolidates fines or small particles into larger particles [4] and gel contents increase, mechanical properties of materials increase introducing a possible reaction between both components [3]. $\mathrm{Na}_{2} \mathrm{SiO}_{3}$ can be applied to protect metals for years against corrosion [2]. The SEM analysis assessment, thermal and gravimetric analysis has presented that silicate solution dilution and the grain size affect the silicate content in the granular system. The dry temperature is an important parameter that exploits the physical chemistry of the consolidation. It has been suggested that the mechanical performance of the examined materials are directly affeced by all these parameters [3]. Omar et al. [6] concluded that alkaline activator (AA) mortar can be used as an overlay material in the repairing works to bond old concrete external surfaces with the new one from the results of their pull-out test.

Table 1 Physical and chemical properties of the sodium silicate solution

\begin{tabular}{ll}
\hline Properties & Data $^{\mathrm{a}}$ \\
\hline $\mathrm{SiO}_{2} / \mathrm{Na}_{2} \mathrm{O}$ ratio & 2.00 \\
$\% \mathrm{Na}_{2} \mathrm{O}$ & 14.70 \\
$\% \mathrm{SiO}_{2}$ & 29.70 \\
$\% \mathrm{Total}$ solid & 44.40 \\
$\%$ Water content & 55.55 \\
$\%$ Water insoluble & 0.05 \\
Density, Baume $\left({ }^{\circ} \mathrm{Bé}\right)$ & 50 \\
Specific gravity at $\left(20^{\circ} \mathrm{C}\right) \mathrm{g} / \mathrm{cm}^{3}$ & 1.526 \\
Colour and appearance & Clear \\
& white \\
pH & liquid \\
\hline
\end{tabular}

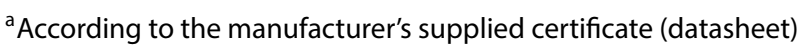

\section{Materials properties}

Analytical grade sodium hydroxide $\mathrm{NaOH}$ in flake form ( $\mathrm{NaOH}$ with $98-99 \%$ purity), from EL-Nasr Co. for intermediate chemicals; one of the national service companies attributed to Egyptian Armed Forces, 6th October City. For $\mathrm{NaOH}$, it is commercially available in Egypt with 97-98\% purity in flake or pellet form [7]. The source of the $\mathrm{Na}_{2} \mathrm{SiO}_{3}$ solution is Egyptian Co., the Suez area. Table 1 illustrated the physical and chemical properties of $\mathrm{Na}_{2} \mathrm{SiO}_{3}$ solution. Figure 1 presented preparing of alkaline activator coating materials AACM.

\section{Experimental program}

The main purpose of this paper is to illustrate the influence of AACM on the performance of the physical concrete external surface properties such as (colour of visual appearance, Sorptivity, water permeability, and sulfate-attack).

\subsection{Colour of visual appearance}

The colour of all samples is tested by the visual inspection at the lab faculty of Industrial Education, Suez university.

\subsection{Sorptivity}

Sorptivity is a property related to the capillary effect of the concrete external surface. When the concrete surface was coated with AACM, the movement of water inside the concrete external surface was delineated by the classical square-root-time relationship which has been coated with AACM. The absorption was estimated according to ASTM C1585-04 as presented in Eq. (3), [8]: according to the following sequence. The AACM was coated for concrete specimens, the specimens to dry the surface and weighed to nearest-gram as presented in Fig. 5, then the face of the specimen will be submerged in water at room temperature for square root time, the specimens are withdrawn
Fig. 1 Preparing of alkaline activator coating materials AACM. a Solids $\mathrm{NaOH}$ in pellet form $\mathbf{b}$ the solids $\mathrm{NaOH}$ dissolved in water $\mathbf{c ~ N a}{ }_{2} \mathrm{SiO}_{3}$ solution
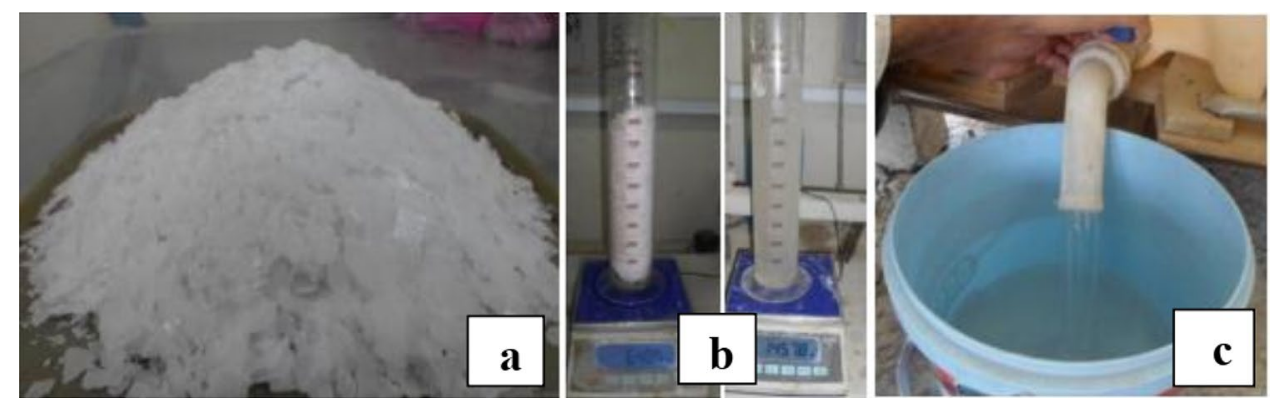
from the water and the excess external surface moisture removed, then weight the sample to the nearest gram. Following ASTM C1585-04, the water absorption ratio shall be calculated to ensure the performance and efficiency of AACM.

\subsection{Water penetration}

The water-penetration test was carried out utilizing the automatic concrete water-penetration apparatus at three cells, presented Fig. 7g. Water-penetration test specimens were cubes $100 \mathrm{~mm}$ specimens. The specimens were kept underwater pressure of 5 bar for $24 \mathrm{~h}$. then the cubes specimens were crushed under the compression test machine by the indirect tensile method to Measure for the waterpenetration depth into the cubes specimens concrete. The voids are existed due to the entrapped air during mixing ingredients may provide passages for water migration within the concrete by advancing deterioration. It is assumed that coating concrete with AACM can eliminate or reduce the size of these voids, leading to the densification of concrete as presented in Fig. $7 \mathrm{~g}$.

\subsection{Sulfate-attack}

The cement concrete cubes were then subjected to durability study in the chemical environment. Figure 8 cement concrete cubes were immersed in a $10 \%$ solution of sodium sulphate $\left(\mathrm{Na}_{2} \mathrm{SO}_{4}\right)$ in a 20-I container for 90 days to study and evaluate the effect of the $\mathrm{Na}_{2} \mathrm{SO}_{4}$ on the weightloss of concrete.

\section{Mix design}

The cement alkaline activator was prepared using three different ratios which are $0.0,0.5$ and 1.0. The $\mathrm{Na}_{2} \mathrm{SiO}_{3}$ / $\mathrm{NaOH}$ solution was prepared by using two different ratios which are 1.5 and 2.5. The $\mathrm{NaOH}$ solution was prepared by dissolving $\mathrm{NaOH}$ pellets in water. The molarity of $\mathrm{NaOH}$ is kept fixed at $\mathrm{M} 14$ [9]. The $\mathrm{Na}_{2} \mathrm{SiO}_{3}$ is added to increase the process of polymerization $[10,11]$. The $\mathrm{NaOH}$ with $97-98 \%$ purity, in flake or pellet form, is commercially available, see Fig. 1a. The solids should be dissolved in water to make a solution with the required concentration before $24 \mathrm{~h}$ from the test carry-out. See Fig. 1b. The concentration of $\mathrm{NaOH}$ can vary in the range between 10 molar and 16 molars; however, 14 molar solution is adequate for most applications (see Fig. $1 \mathrm{a}$, b). Also, properties of $\mathrm{Na}_{2} \mathrm{SiO}_{3}$, as shown in Table 1 and Fig. 1c. AACM is activated by adding the alkaline activator gradually with several ratios to the cement during the mixing process at ambient temperature. All $\mathrm{Na}_{2} \mathrm{SiO}_{3}$ solutions are alkaline with $\mathrm{pH}$ from 10 to 13 according to the concentration of $\mathrm{SiO}_{2} / \mathrm{Na}_{2} \mathrm{O}$ ratio in the solution and data analysis from the manufacturer's supplied certificate (data-sheet) as shown in Table 1. Moreover, the cement is an alkaline-substance that has a $\mathrm{pH}$ of 11.5. At the start of the reaction, the cement $\mathrm{pH}$ reaches approximately 13.6 at its maximum level in the presence of $\mathrm{NaOH}$ as shown in Table 2. With increasing the percentage of cement in the mixture, the degree of $\mathrm{pH}$ increases up to 13.6 due to the high degree of $\mathrm{pH}$ for the cement and $\mathrm{Na}_{2} \mathrm{SiO}_{3}$. The mixture resulting in a highly alkaline medium which is more beneficial for use on the external concrete surface. All mixtures used in the research are designed to be capable as a coating for external concrete surfaces by applying several trial mixtures. Table 2 and Fig. $2 a-c$, presented mix design formulations of molar compositions to obtain AACM.

\section{Methodology and mechanism}

AACM can be classified by the effect of reaction type or condensation type on the concrete exterior surface within the limits of the concrete cover depth. Figure 3, presented the advantage of the reaction type material for AACM and its effect on the chemical composition of

Table 2 Mix design formulation of AACM

\begin{tabular}{|c|c|c|c|c|c|c|c|}
\hline $\begin{array}{l}\text { Cement/alka- } \\
\text { line activator }\end{array}$ & Molarety (M) & $\mathrm{Na}_{2} \mathrm{SiO}_{3} / \mathrm{NaOH}$ & Cement (g) & $\mathrm{Na}_{2} \mathrm{SiO}_{3}(\mathrm{~g})$ & $\mathrm{NaOH}(\mathrm{g})$ & $\mathrm{PH}$ & Figure \\
\hline Control & \multicolumn{6}{|c|}{$\begin{array}{l}\text { Cement concrete specimens cube } 10 \times 10 \times 10 \mathrm{~cm} \text {, without curing by alkaline activator coat- } \\
\text { ing materials AACM as presented in Fig. } 2 \mathrm{a}\end{array}$} & Presented in Fig. $4 a$ \\
\hline AACM-0.0 & $M_{10}$ & 1.5 & 0.0 & 120 & 80 & 12.64 & Presented in Figs. $2 \mathrm{a}$ and $4 \mathrm{~b}$ \\
\hline AACM-0.0 & $M_{10}$ & 2.5 & 0.0 & 142.85 & 57.15 & 12.83 & \\
\hline AACM-0.5 & $\mathrm{M}_{10}$ & 1.5 & 100 & 120 & 80 & 13.05 & Presented in Figs. $2 \mathrm{~b}$ and $4 \mathrm{c}$ \\
\hline AACM-0.5 & $\mathrm{M}_{10}$ & 2.5 & 100 & 142.85 & 57.15 & 13.43 & \\
\hline AACM-1.0 & $\mathrm{M}_{10}$ & 1.5 & 200 & 120 & 80 & 13.53 & Presented in Figs. $2 \mathrm{c}$ and $4 \mathrm{~d}$ \\
\hline AACM-1.0 & $\mathrm{M}_{10}$ & 2.5 & 200 & 142.85 & 57.15 & 13.64 & \\
\hline
\end{tabular}


Fig. 2 a Mix AACM-0.0 b mix AACM-0.5 c mix AACM-1.0

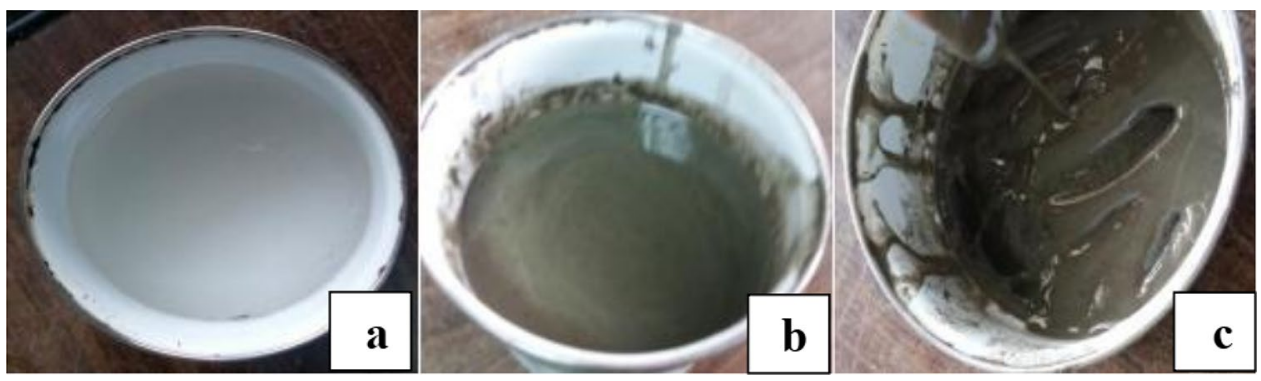

Fig. 3 Characteristics of silicate-based face penetration materials (reaction type)

$$
\begin{aligned}
& \text { porous layer on the } \\
& \text { entire concrete surface } \\
& \text { absorbed water in to } \\
& \text { the concrete layer }
\end{aligned}
$$

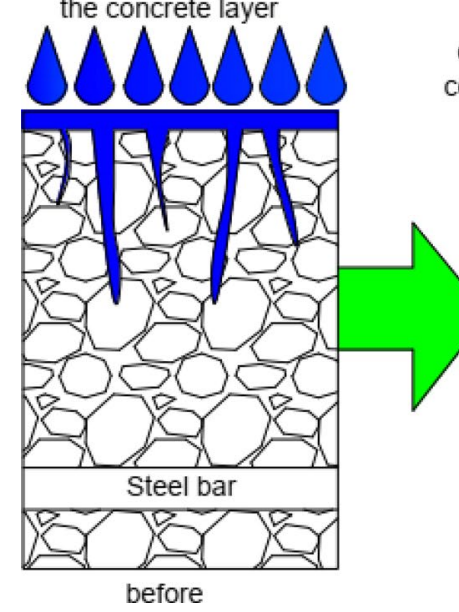

nonporous layer on the entire concrete surface

Coating concrete surface by cement-based alkaline activator
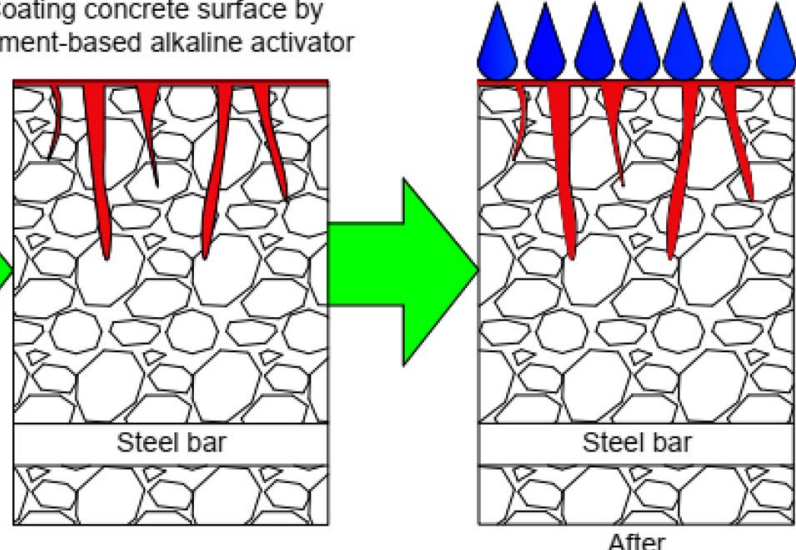

cement on the concrete surface. This type of cementbased on geopolymer coating materials (CBGCM) produces $\left(\mathrm{C}_{3} \mathrm{~S}_{2} \mathrm{H}_{3}\right)$ calcium silicate hydrates by the reaction of $(3 \mathrm{CH})$ calcium hydroxides in the cement with silicate in the AACM. These effects happen when the reaction type material is in a wet or dry condition at the surface of cement concrete coated with AACM because it contains water as a main component of AACM. Alkaline activator coating materials AACM has been developed to be of the same reaction type material of cement concrete. Figure 3 , presented the characteristics of the condensation type material for AACM. This condensation type material hardens the external concrete surface when used in the dry condition and ambient temperatures. Equation (1) illustrates the chemical reaction between the concrete components and sodium silicate (reaction type), while Eq. (2) illustrated the reaction between the concrete components and $\mathrm{K}_{2} \mathrm{OxSiO}{ }_{2}$ [3]. The performance of the materials varies depending on their main component as presented in Eq. (1) and Eq. (2).

$$
\begin{aligned}
& \mathrm{Na}_{2} \mathrm{O} \mathrm{SiO}_{2}+x \mathrm{Ca}(\mathrm{OH})_{2}+y \mathrm{H}_{2} \mathrm{O} \rightarrow x{\mathrm{CaO} x \mathrm{SiO}_{2}}_{2} \mathrm{xH}_{2} \mathrm{O} \\
& \quad+2 \mathrm{NaOH}+(x+y-z-1) \mathrm{H}_{2} \mathrm{O}
\end{aligned}
$$

$$
\begin{aligned}
& \mathrm{K}_{2} \mathrm{O} \mathrm{SiO}_{2}+x \mathrm{Ca}(\mathrm{OH})_{2}+y \mathrm{H}_{2} \mathrm{O} \rightarrow x \mathrm{CaO} \times \mathrm{SiO}_{2} \times z \mathrm{H}_{2} \mathrm{O} \\
& +2 \mathrm{KOH}+(x+y-z-1) \mathrm{H}_{2} \mathrm{O}
\end{aligned}
$$

\section{Discussions}

\subsection{Visual appearance}

From Fig. $4 a-d$ all of the specimens changed in colour from grey Fig. 4a to glassy bright surface Fig. 4b, light grey Fig. 4c, and dark grey Fig. $4 d$ due to coating of the surface with alkaline activator coating materials AACM with and without activated cement, respectively. consequently, alkaline activator coating materials AACM changed the visual appearance of the concrete specimen to the best as presented in Fig. $4 \mathrm{~d}$.

\subsection{Sorptivity}

Sorptivity is a property associated with the capillary influence of concrete exterior surface. When the concrete exterior surface was coated with AACM, the movement of water inside the concrete surface was delineated by the 


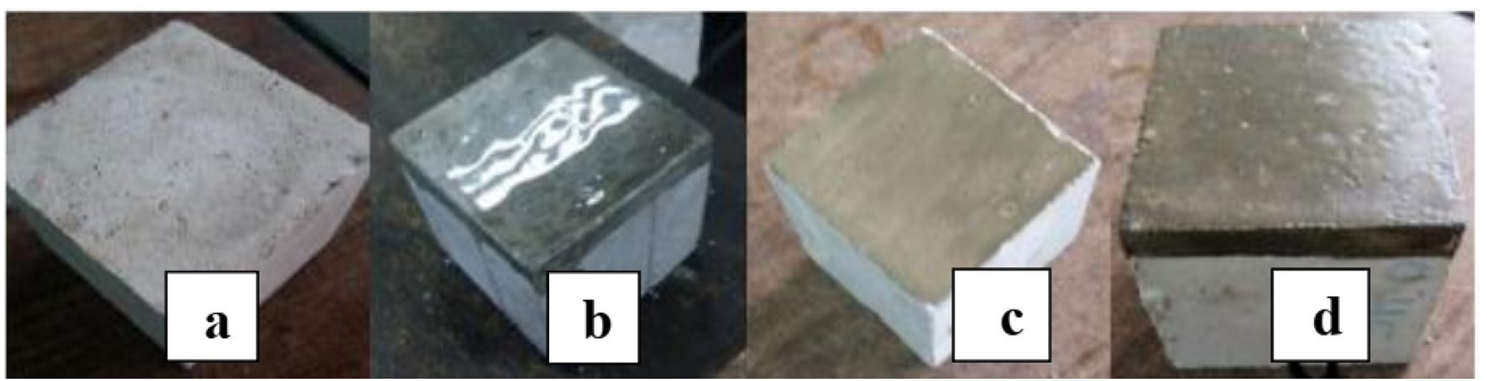

Fig. 4 Visual appearance $\mathbf{a}$ cube before coating $\mathbf{b}$ cube after coating with mix AACM- 0.0 c cube coating mix AACM- 0.5 d cube coating mix AACM-1.0

classical square-root-time relationship and type of surface which has been coated with AACM. The absorption was estimated according to ASTM C1585-04 as presented in Eq. (3), [8]:

$$
\mathbf{I}=\mathbf{M t} / \mathbf{A \rho}
$$

where I-the absorbed volume after time t per unit area of inflow surface $\left(\mathrm{mm}^{3} / \mathrm{mm}^{2}\right)$; Mt - the change in specimens mass at the time $t\left(\mathrm{~mm}^{3}\right) ; \boldsymbol{\rho}$-the relative density of water; $\mathbf{A}$ - the cross-sectional area in contact with the fluid $\left(\mathrm{mm}^{2}\right)$.

The sorptivity is given for the concrete mixture in Fig. 5, at the age of the samples 56 days. Each set of plots illustrated refers to the average of three samples tested.

In this relationship, water absorption into the porous material increases with the increase of the square-root of the elapsed time " $t$ " [12].
Figures 5 and 6 presented the test setup and the cumulative mass gained per exposed exterior surface area against the square root of time where the slope of the linear portion is the measurement of sorptivity. The figures presented that the value of sorptivity decreases for concrete specimen coated with AACM without cement activated and decreases much more for concrete specimen coated with AACM with cement activated for mixes with cement/alkaline ratios $0.0,0.5$ and 1.0 while the $\mathrm{Na}_{2} \mathrm{SiO}_{3} /$ $\mathrm{NaOH}$ solution ratios are 1.5 and 2.5. In general, the use of AACM has reduced the water sorptivity of the concrete specimen. The reason is related to porosity and capillarity which was reduced by the coating of a concrete surface with AACM. Furthermore, as the cement activator in AACM increases, the pore area is reduced due to the increased viscosity which leads to the creation of a nonporous layer on the entire concrete surface.
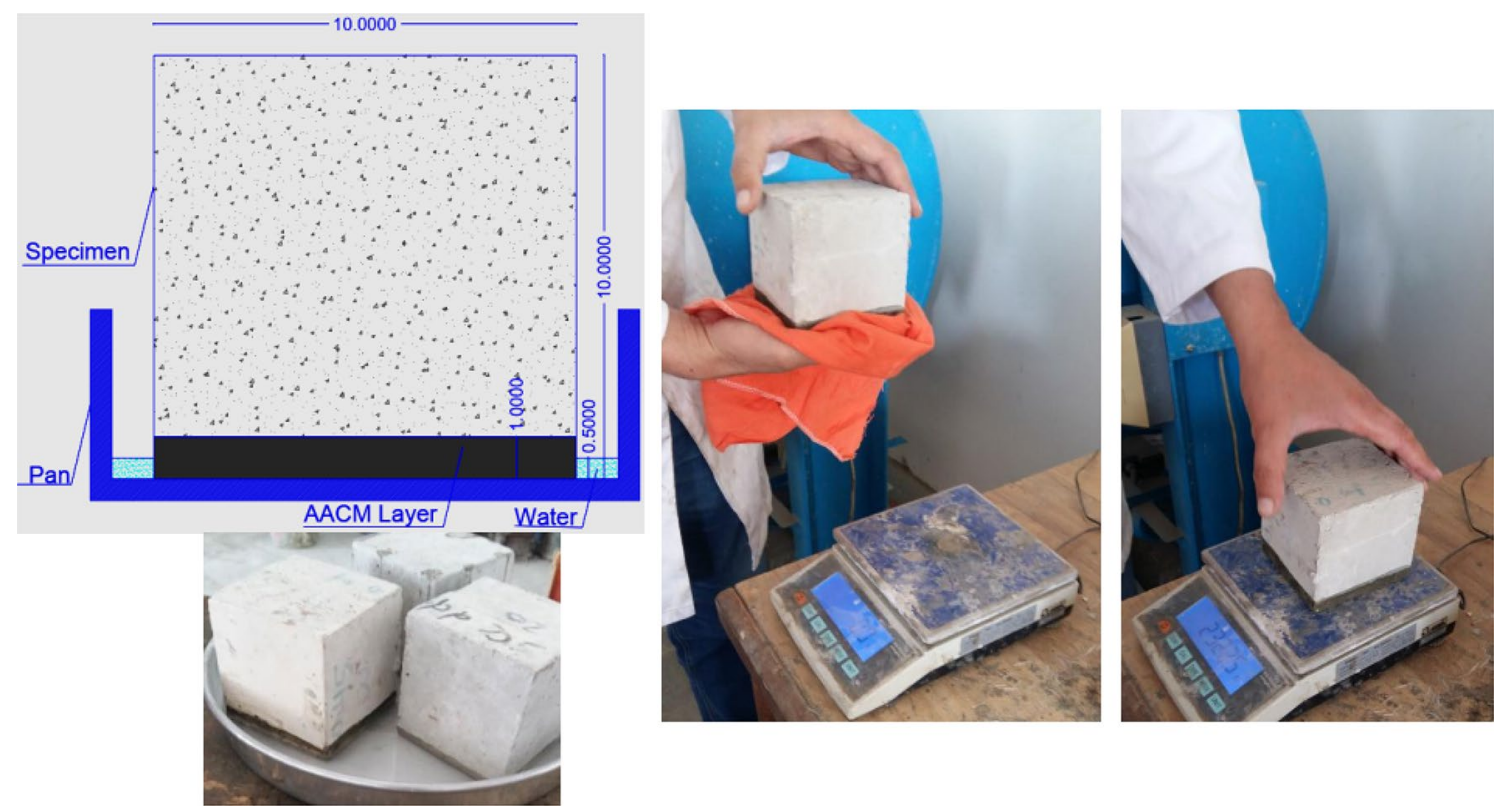

Fig. 5 Sorptivity test setup 


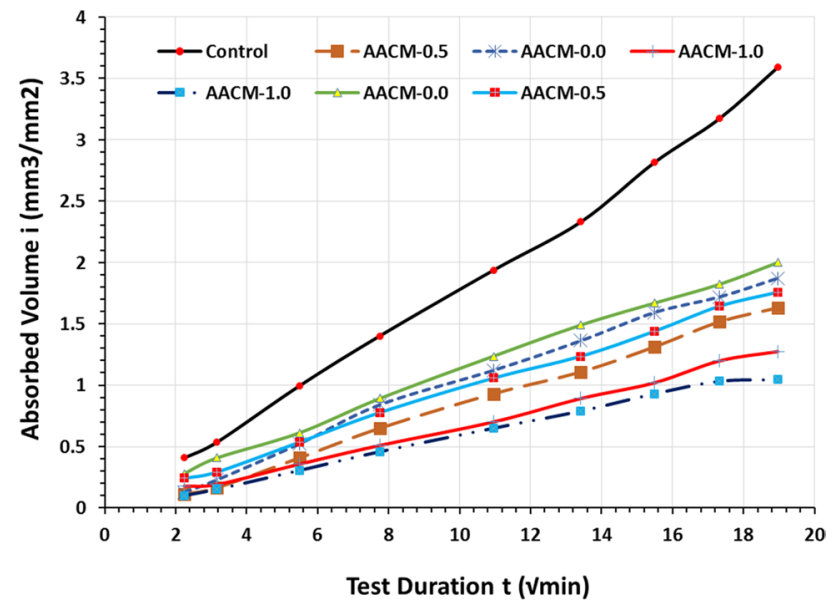

Fig. 6 Cumulative sorptivity per unit area with square root time for specimen coated with alkaline activator coating materials AACM

\subsection{Water penetration}

The voids were formed due to the entrapped air during mixing ingredients, may provide passages for water migration within the concrete thereby advancing deterioration. It is assumed that coating concrete with AACM can eliminate or reduce the size of these voids, leading to the densification of concrete.
The water penetration of concrete is represented by the average of water penetration depth into concrete determined after $24 \mathrm{~h}$ under the pressure of 5 bar. The basic step for such a depth of penetration test is to apply water under pressure to one external surface of the concrete cube sample $(100 \times 100 \times 100 \mathrm{~mm})$ for a determined time and then the specimens are split perpendicular to the external concrete, marked and the depth of penetration is measured visually with the measure tool. It can be observed that the average penetration depth, decreases as the cement content in the mix of AACM increases as shown in Fig. $7 f$, the water penetration depth around between $2.4 \mathrm{~mm}$. AACM coating impregnated in concrete exterior surface filling the voids as presented in Fig. $7 \mathrm{a}-\mathrm{g}$.

\subsection{Sulfate attack}

The cement concrete cubes were then subjected to durability study in the chemical environment (Fig. 8). Figure 9 cement concrete cubes were immersed in a $10 \%$ solution of sodium sulphate $\left(\mathrm{Na}_{2} \mathrm{SO}_{4}\right)$ in a twenty-litre container for 90 days to study and evaluate the effect of the solution of $\mathrm{Na}_{2} \mathrm{SO}_{4}$ on the weight loss of concrete. It can be observed that the coating with the AACM improved the impedance against $\mathrm{Na}_{2} \mathrm{SO}_{4}$ penetration in the unit weight testing, because the alkaline activator coating materials AACM caused densification on the exterior surface of concrete specimens, offering better water-proofing performance
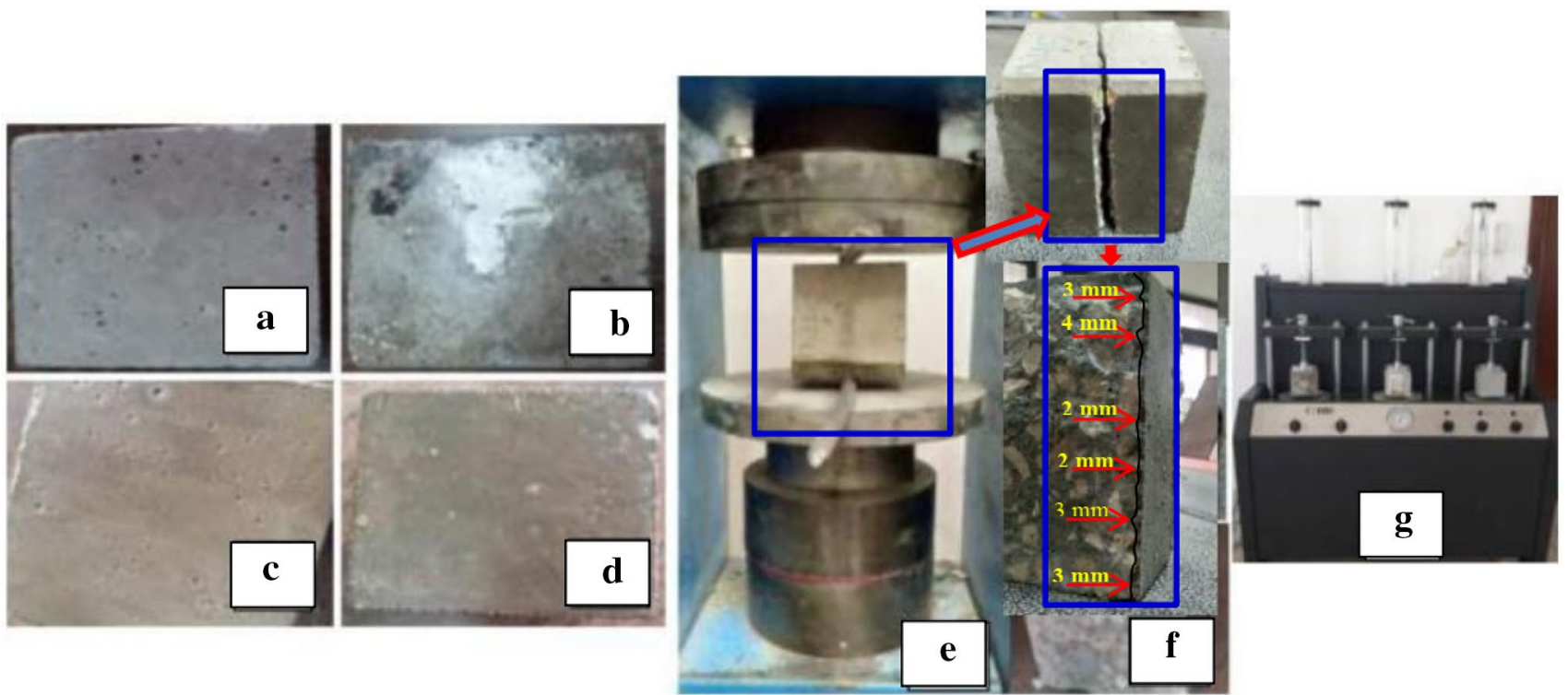

Fig. 7 a Cube before coating b cube after coating with mix AACM- 0.0 c cube coating mix AACM- 0.5 d cube coting mix AACM-1.0 e test machine $\mathbf{f}$ penetration depth $\mathbf{g}$ test setup 


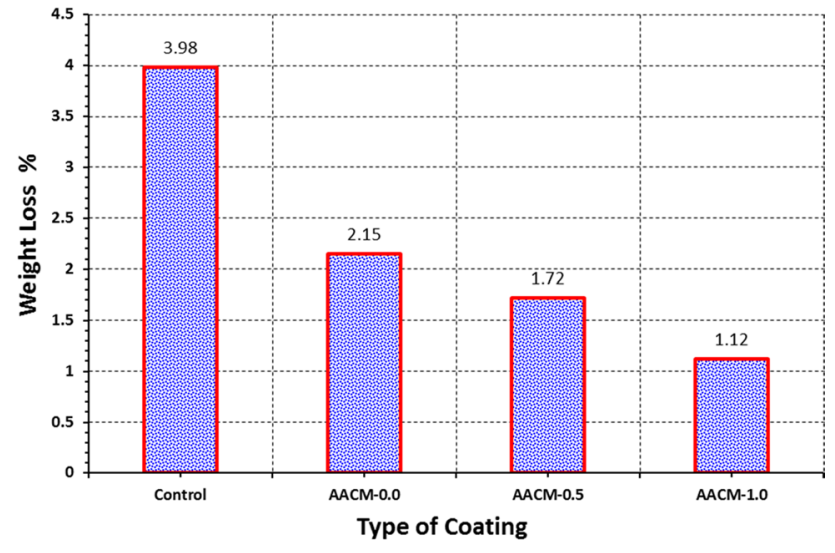

Fig. 8 The effect of 10\% Sulfate attack on the weight loss of concrete exterior surface coated with the AACM

including liquid absorption inside the concrete. The exterior surface deterioration was observed in Sodium Sulphate $\mathrm{Na}_{2} \mathrm{SO}_{4}$ immersion for concrete without the coating of the concrete face with AACM. However, for the concrete face which has been coated with AACM, the concrete face deterioration and weight loss decrease by a percentage of $45.97,56.78$ and 71.85 for specimens $0.0,0.5$ and 1.0, respectively as presented in Fig. 8 .

\section{Conclusions}

This study concludes the results for the performance of alkaline activator coating materials containing cement which are listed as follows:

1. Absorption is reduced following the application onto the concrete exterior surface and it is protected against the external factors such as humidity.

2. Composition of AA consists of $\mathrm{Na}_{2} \mathrm{SiO}_{3}$ and $\mathrm{NaOH}$ is water-based and does not cause any risk for the environment and human health after preparation except in the case of direct contact with skin or eye. Also, because $\mathrm{NaOH}$ can cause irritation eyes, skin; an allergic reaction; skin burns; and many others. Workers may be harmed from exposure to $\mathrm{NaOH}$. Therefore, attention should be paid for safety at work when using such as these materials, like wearing rubber gloves and goggle when handling the chemical and mixtures.

3. Alkaline activator (AA) coating cheaper than oil-based products AA coating cheaper than oil-based products according to the Egyptian market for the sale of modern building materials products [6].

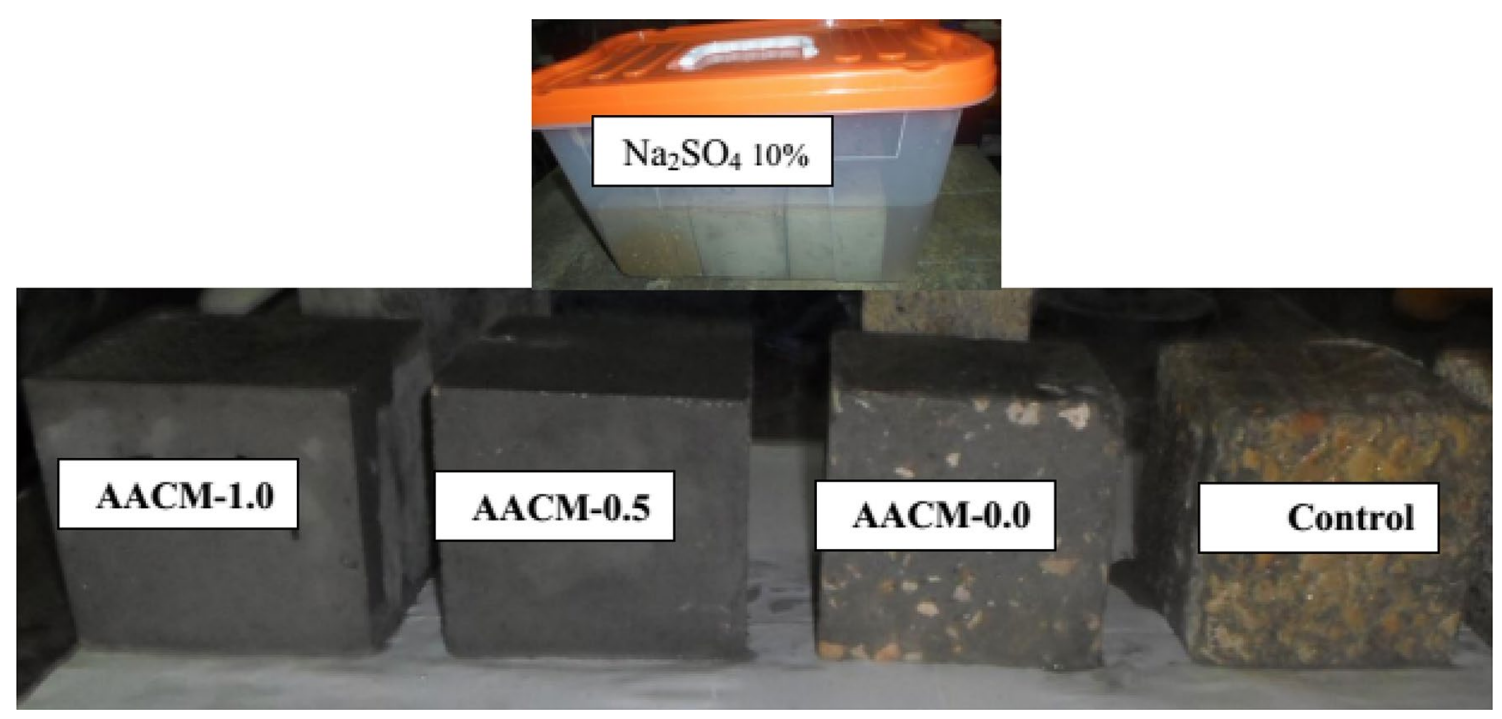

Fig. 9 Effect of $10 \%$ sulfate attack on the weight loss of concrete exterior surface coated with the AACM 
4. Absorption of the mixture component on concrete exterior surface led to decrease Sorptivity, Water penetration as well as reducing the deterioration of concrete exterior surface in the harsh environments.

\section{Compliance with ethical standards}

Conflict of interest On behalf of all authors, I pledge that I am not involved in the interests of the financial, commercial, legal, or professional relationship with other organizations, or with the people I worked with them, that could influence my research.

\section{References}

1. Inazumi S, Inazawa T, Soralump S, Saiki O, Matsumoto H (2017) Assessment of potassium silicate based surface penetration materials with low viscosity in the repair of concrete structures. Int J Geomater 12:163-170

2. Hahn JJ, McGowan NG, Heimann RL, Barr TL (1998) Modification and characterization of mineralization surface for corrosion protection. Surf Coat Technol 109:403-407

3. Ibrahim GA, El-Hariri TYMA, Mousa AS, Gaber MAW (2012) Utilization of sodium silicate solution as a curing compound of fresh concrete. J Am Sci 8:61-66

4. Tognonvi MT, Kouassi SS, Maeda T, Soro J, Rossignol S, Bonnet $\mathrm{J}$ (2010) Use of sodium silicate gel as a precursor of the binder for cold consolidated materials. Adv Sci Technol 69:57-62
5. Lucas S, Tognonvi MT, Gelet J-L, Soro J, Rossignol S (2011) Interactions between silica sand and sodium silicate solution during consolidation process. J Non-Cryst Solids 357:1310-1318

6. Ibrahim OMO (2015) Production of high performance geopolymer concrete (green concrete) Ph.D. Faculty of Industrial Education, Civil Construction and Architectural Dept., Suez University, Egypt

7. ECP 203-2016, Egyptian code of practice for concrete structures. Housing and Building Research Center, Cairo

8. Adam AA (2009) Strength and durability properties of alkali activated slag and fly ash-based geopolymer concrete. M.Sc. School of Civil, Environmental and Chemical Engineering RMIT University Melbourne, Australia

9. Omar OM, Abd Elhameed GD, Heniegal AM, Mohamadien HA (2015) Effect of crashed stone on properties of fly ash basedgeopolymer concrete with local alkaline activator in Egypt. Int J Civ Environ Eng 9:1357-1366

10. Omar OM, Heniegal AM, Abd Elhameed GD, Mohamadien HA (2015) Effect of local steel slag as a coarse aggregate on properties of fly ash based-geopolymer concrete. Int J Civ Environ Eng 9:1452-1460

11. Mohamadien HA, Heniegal AM, Abd Elhameed GD, Omar OM (2015) Properties of geopolymer mortar containing cement kiln dust (bypass) as partial replacement material for low calcium fly ash. Port-Said Eng Res J 7:265-277

12. Dutta $D(2010)$ Influence of silicious and calcious material as an additive on the performance of fly ash based geopolymer paste and mortar. Thesis M.Sc. Department of Civil Engineering Faculty of Engineering \& Technology Jadavpur University, Kolkata

Publisher's Note Springer Nature remains neutral with regard to jurisdictional claims in published maps and institutional affiliations. 